\title{
Gamifying the process of innovating ${ }^{1}$
}

\author{
Agnessa Shpakova, Viktor Dörfler, Jill MacBryde
}

Department of Business Management, Heriot Watt University, Edinburgh, UK, The Avenue, Currie EH14 4AS, +44 (0) 7563244 742, a.shpakova@hw.ac.uk

Department of Management Science, University of Strathclyde, Glasgow, UK, 199

Cathedral Street, G4 OQU, +44 (0)141548 4540,viktor.dorfler@strath.ac.uk

The York Management School, University of York, York, UK, Freboys Lane, Heslington, YO10 5GD, +44 (0) 1904 325846, jill.macbryde@york.ac.uk

Corresponding author: Agnessa Shpakova, Department of Business Management, Heriot Watt University, Edinburgh, UK, The Avenue, Currie EH14 4AS, +44 (0) 756 3244 742, a.shpakova@hw.ac.uk

DOI: $10.1080 / 14479338.2019 .1642763$

Acknowledgements: We would like to thank the company Pryaniki and particularly Evgeniya Lyubko for sharing their experience with us.

${ }^{1}$ This is the peer reviewed version of the following article: Agnessa Shpakova, Viktor Dörfler \& Jillian MacBryde (2019) 'Gamifying the process of innovating', Innovation: Organization and Management, DOI: $10.1080 / 14479338.2019 .1642763$, which has been published in final form at http://dx.doi.org/10.1080/14479338.2019.1642763. This article may be used for non-commercial purposes in accordance with Routledge Rights and Permissions. 


\title{
Gamifying the process of innovating
}

\begin{abstract}
Gamification is a new, rapidly growing trend impacting many areas of business such as learning and marketing. It has also been predicted to revolutionize the process of innovating. However, there have been very few examples of gamification supporting the innovating process within the academic literature. The departure point for this thought piece is whether this prediction can ever be fulfilled. We intend to open a discussion about the ways in which gamification and innovating may intertwine and how the mindset and the toolset of gamification can support the process of innovating. In particular, we showcase and review a set of examples of gamifying innovating activities from both research and practice. Marrying this review of practice with academic evidence from innovation literature, we highlight some gaps and explore potential directions for further research.
\end{abstract}

Keywords: gamification; innovation; innovating process; innovation management

\section{Introduction}

Following the early successful examples of gamification in innovating, in 2012 Gartner Group $^{2}$ predicted that by 2015 more than $50 \%$ of innovation processes will be gamified (Burke, 2012). Whilst no-one has been officially measuring this, experts would agree that we are still far from this prediction. Although this prediction seems to have been too ambitious, we believe that gamification has already demonstrated great potential. Taking a process view of innovation, in this paper we first present some of the evidence of where gamification is supporting the processes of innovating. Then we explore activity areas where gamification is becoming mainstream, and expose the areas where

\footnotetext{
${ }^{2}$ Gartner, Inc. is an international information technology and advisory company. Every year it publishes a Hype Cycle report of emerging technologies that are worth paying extra attention to, assessing their maturity level and projecting when each of them reaches its full potential (source: www.gartner.com).
} 
it is less commonly used. We put forward the view that gamification does have significant potential to change the process of innovating. The paper concludes by exploring potential directions for research that will advance our understanding and speed up adoption in practice.

With this paper we contribute to the discussion about the use of play (Dodgson, 2017) and games (Agogué, Levillain, \& Hooge, 2015) in organisations, by exploring the use of gamification in the "innovating" process, where gamification is broadly understood as a process of using game elements in a non-gaming environment (Deterding, Dixon, Khaled, \& Nacke, 2011; Werbach \& Hunter, 2012). This is an opinion paper informed by the examples found both in literature and practice. By reviewing and synthesizing existing experience we outline directions for further research, which in turn might advance our understanding of how gamification affects the innovating process, and therefore bring practice closer to Gartner's vision.

To frame our investigation and discussion we adopt a process view of innovation and use a popular model of the innovation process, Tidd et al (2005), although there are many others, such as Van de Ven et al. (2000) and Cooper (1983) which could also have been used as a guiding framework. We use the phases of this model to present and discuss examples of gamification found in both the academic literature and practice. Thus our paper contributes to the ongoing conversation in this area by aggregating the accumulated experience of gamified innovating and demonstrating the complexity of the studied phenomenon by visualising the interconnectivity of various gamification elements.

Before doing this, the following section provides an overview of the fields of gamification, games and play in the context of innovation. The next section draws on the examples found in literature and practice and discusses approaches to gamifying 
each phase of the innovating process. The final section discusses the findings and the implications to theory and practice.

\section{Play, games and gamification in the context of innovation}

Innovation is always about thinking and doing differently than before; thinking and doing the same is about preserving the status quo. However, thinking and doing differently means breaking away from the usual patterns, which often work very well. In many ways, many people find it difficult to do this when they work, although they often find the same easy if they are playing games. This suggests that gamification, in the sense of bringing game elements into non-game contexts, can perhaps be well aligned with the process of innovating, it may help to think and do differently.

In the introduction we have mentioned three related concepts: play, games and gamification. The three concepts are interrelated and are likely to be mutually reinforcing, and therefore it is necessary to discuss the meaning of each of them in more detail in order to clarify the focus of this paper. From the point of view of system design, gamification and games are seen as rule-based, goal-oriented forms of playing, in contrast with free-form exploratory play (Deterding, 2012), a distinction between "paidia" (playing) and "ludus" (gaming) (Caillois, 1961). But ultimately both forms are fundamental to human culture (Huizinga, 1949) and perceived as fun that can change the state of mind towards engaging in the activity for the sake of it (McGonigal, 2015).

Situationally in an organisational setting gamification is applied to the core activities to make them more game-like. Playing, on the other hand, can be used complementary to work, for instance, to unleash creativity by facilitating experimentation (Gray, Brown, \& Macanufo, 2010; Hohmann, 2006; McGonigal, 2014), or to help reach the state of mind that allows a player to immerse oneself in both play and work with equal intensity (Nath \& Metiu, 2016). From this perspective 
playing is different from play and can be applied to games as well (Simpson, Tracey, \& Weston, 2018). For instance, video games are quite often played for entertainment, while other games are purposefully designed for training and learning, and are sometimes referred to as 'serious games' (Deterding et al., 2011). Such applications are closer to the concept of gamifying a core activity, and sometimes it is difficult to distinguish between gamification and games; however, serious games are not in the focus of this paper. Finally, gamified activities might resemble a full-fledged game, and in this paper we present such examples. Figure 1 clarifies the types of examples that we might observe in this paper.

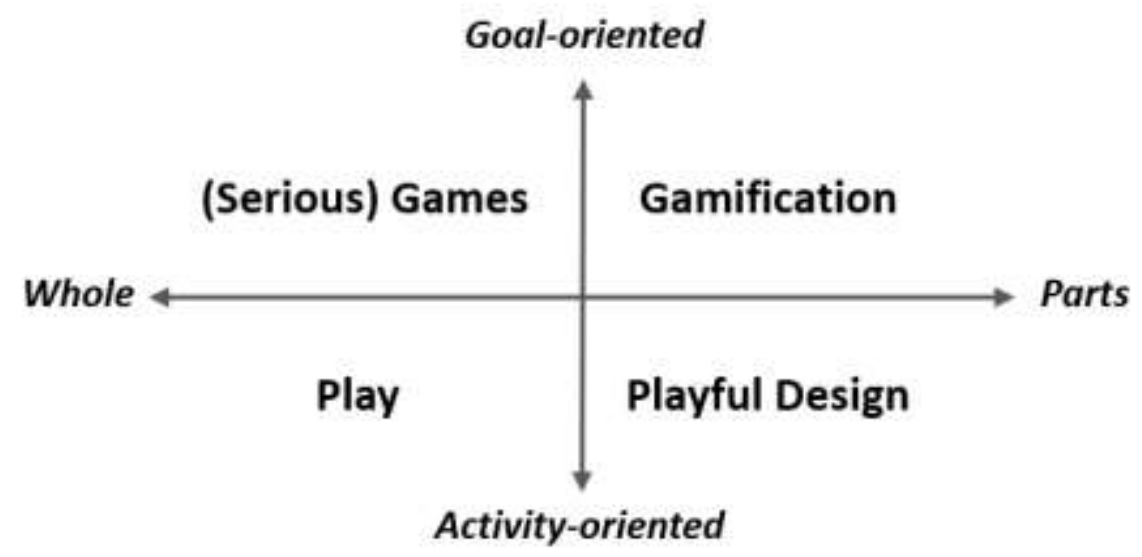

Figure 1. Classification of game-play. Adapted from (Deterding et al., 2011).

The type of thinking that encourages experimentation, the so-called divergent or trial and error thinking (Guilford, 1968; Runco, 1991; Runco \& Acar, 2012), is considered to be essential for innovating and developing innovative capabilities (Roth, Schneckenberg, \& Tsai, 2015; Schulz, Geithner, Woelfel, \& Krzywinski, 2015). From this perspective play provokes the imagination by inviting for the exploration of the possibilities, or even of what is currently considered impossible, free of rules and purpose (Brown, 2009). Then again, games encourage divergent thinking by creating a positive relation with failure (Lee \& Hammer, 2011), which is an essential part of the 
learning experience in games (Gee, 2008), in seeking to uncover the rules and structure of the game (Simpson et al., 2018). Thus play and game seem to be complementary to each other, where game is a form of play that was given a purpose and that requires hard work (McGonigal, 2014).

One of the defining characteristics of gamification, and games for that matter, is the use of game elements that construct a gameful design. Most researchers classify game elements by their levels of abstraction, varying from two (Blohm \& Leimeister, 2013) to five (Deterding et al., 2011). These classification are predominantly based on the (re-)interpretation of the MDA (mechanics, dynamics and aesthetics) framework of Hunicke et al. (2004) developed for game design; however, these levels are not always interpreted the same way (Shpakova, Dörfler, \& MacBryde, 2017). In this paper we have adopted the framework of Werbach and Hunter (2012), because it is aligned with the MDA framework and suggests a logical hierarchy of game elements, starting from the components (elements we interact with), through mechanics that bind them together, to the dynamics that suggest the types of behaviour that we want the system to nurture (Figure 2). The distinction between dynamics and other level is particularly useful for further review of the cases, because it will help to understand the differences between various approaches to the gamification of innovating. 


\section{Dynamics}

are the big-picture

aspects of the gamified

system that you have to

consider and manage but

which can never directly enter

into the game.

\section{Mechanics}

are the basic processes that drive the action

forward and generate player engagement

\section{Components}

are the specific instantiations of mechanics and dynamics.

Figure 2. Classification of gamification elements. Source: (Werbach \& Hunter, 2012).

However, we believe that, although it is important to distinguish between different game elements, a strong focus on the classification of game elements might shift the attention to the system design exclusively, and in particular to the most commonly used elements, e.g. points, badges, leaderboards and rewards. This might subsequently limit the perception of the gamification complexity and potential and open the route of gamification criticism. For instance, gamification solutions that are centred around the use of certain game elements are often reward-oriented, and therefore can deter intrinsic motivation of the system users (Deterding et al., 2011; Heeter, Lee, Medler, \& Magerko, 2011; Zuckerman \& Gal-Oz, 2014) or reduce gamification to “pointification” (Werbach \& Hunter, 2012). This raises legitimate concerns of whether the effects of such designs can be sustained on the long term (Hamari, 2013; Nicholson, 2012), or even be fraudulent in nature, where people are tricked into game-like behaviour in a non-gaming environment (Ferrara, 2013), and where gamification can become a surveillance tool (Cohen, 2016). When manipulative factors dominate the discourse, disguised behind buzzwords of the latest business trends of investment 
consultants, then genuine benefits of gamification might be neglected. Thus, we use the above framework merely to identify and study the peculiarities of the identified examples.

\section{Gamifying the innovating process}

The attempts to gamify the innovating process are based on the assumption that it can be managed, at least to some extent. Even though this assumption is a source of disagreement among the scholars (Rogers, 2010; Van de Ven, 2017), there is a general consensus among the researchers in related disciplines about the main phases that an innovative idea is likely to go through on the way to becoming an innovation. There are a number of process models of innovation to be found in the academic literature for example Cooper (1983) or Ulrich \& Eppinger (2000). One of the most commonly adopted frameworks is that of (Tidd et al., 2005). In their view an innovation passes through the phases of: ideation/search, selection, implementation, and capture/evaluation of the results (Figure 3).

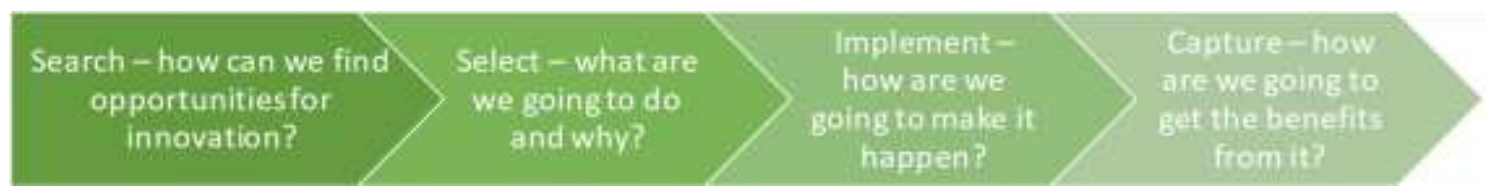

Figure 3. Innovating process. Source: (Tidd et al., 2005).

A process view of innovation was used in this paper for structuring the examples of gamified innovating found in literature and practice. The model is used to illustrate where gamification is being deployed at the moment and the potential in each phase. Many of the examples come from existing academic literature but others are drawn first hand from companies known to the authors and from information in the public domain. A good number of examples from practice were based on the experience of a 
gamification consulting company called Pryaniki ${ }^{3}$ who specialise in gamification for corporate clients and who are, notably, very open about discussing both successes and failures.

\section{Search/Ideation}

One of the most common gamification applications during the search/ideation phase aims at facilitating the process of ideas collection, e.g. by giving participants a reward for an idea. Such incentives are not new and have demonstrated mixed results (Burroughs, Dahl, Moreau, Chattopadhyay, \& Gorn, 2011), but in some of the cases it was observed that turning a reward into a surprise added an element of fun to it and shifted focus from the material value of the gift to the feeling of anticipation and intrigue. Subsequently, surprise can trigger change in how we perceive things (Gudiksen \& Inlove, 2018). Reportedly, the most desired rewards in such initiatives were the gifts that were the cheapest, but presented in public display (e.g. a basket with apples on the desk), and therefore raised the status among colleagues.

Other initiatives take a more holistic approach by giving the participants the tools to interact with ideas and with each other. A mechanic of "investing" points or time in an idea, with subsequent dividends in points if the idea is selected, allows for everyone's participation. It encourages curiosity and exploration of the ideas of others, as well as the expression of one's own ideas, which might give the participants "food for thought" and result in new ideas. When ideas are shared and actively processed within a group, the group members can build on them and enable the emergence of more creative ideas (Hargadon \& Bechky, 2006). Team scoring adds coopetition (e.g. the combination of collaboration within a team and competition between the teams) to

\footnotetext{
${ }^{3}$ http://blog.pryaniky.com/
} 
the dynamics of exploration and expression. Different types of dynamics result in the engagement of different types of participants (Kim, 2018).

Competition has been historically used to initiate innovation (Hutter2011). The same approach is pursued in many gamification ideation solutions (Agogué et al., 2015; Roth et al., 2015; Zimmerling, Hoflinger, Sandner, \& Welpe, 2016), including gamified open innovation solutions, which aim at finding a creative solution to a specific problem (Morschheuser, Hamari, Koivisto, \& Maedche, 2017). Rewards vary in type, and sometimes companies find that monetizing them can have a negative effect. For example, when one company replaced monetary rewards with points that only had status value, the number of ideas increased several-fold. Collaborative interactions seem to be preferred to competition among innovators (El-Nasr et al., 2010), especially in creative professions (Uzzi, 2005). Conversely, introducing a competitive element in a collaborative environment can increase the innovative output (Füller, Jawecki, \& Mühlbacher, 2007) and the quality of ideas (Blohm, Bretschneider, Leimeister, \& Krcmar, 2010). If the participants are involved in both collaboration and competition, they tend to outperform their colleagues (Hutter, Hautz, Füller, Mueller, \& Matzler, 2011). These findings are consistent with experiments in a gamified environment. For instance, in a quest-based ideation process participants expressed a strong preference towards collaboration and coopetition, and their output was perceived as more creative (Zimmerling et al., 2016).

The most commonly used elements, such as points and badges, naturally generate competitive dynamics, because they allow for their comparability. Although a moderate level of competitiveness between collaborating groups of innovators can improve the creative output (Baer et al., 2010), it needs balancing. Gamification provides system designers with tools to regulate this complex group dynamic. Some 
companies often try to regulate the dynamic by embracing group results while lessening the focus on the individual scores (although downplaying individual contributions may have a negative effect on individuals). Others create various types of rewards for different achievements, so as to provide more opportunities to be recognised. Badges allow for such variability, e.g. an 'Einstein' badge for receiving many likes, or a 'thanks from CEO' badge for a creative idea even if it does not move to the pilot phase. An example from the consulting company below illustrates this approach very well:

\section{"Sometimes ideas don't fit in the Idea Bank. But we decided to encourage any new ideas. This way we created the fourth type of reward - "Thank you from the CEO" badge, which is given to those who suggest new ideas for improvement in their work or area of responsibilities." 4}

The above examples facilitate the physical process of ideation (collecting ideas from the individuals), which in many instances might harvest more and better ideas than the collective effort of multidisciplinary teams (Gilson \& Litchfield, 2017). Gamifying ideation can also facilitate cognitive processes. In themed competitions, e.g. an investment market or a space exploration program, participants can try on new characters and change their behaviour to fit in a new persona. This playful behaviour allows for experimentation, while being behind the mask of a new character creates a sense of being in a safe environment, where trying new things is permitted and accepted. By engaging in the game, the participants may enter a playful state of mind, which is fundamentally exploratory (Johnson, 2016). Narratives, which often accompany themed competitions, can "kick" participants out of their usual thinking patterns and help to create new ideas. The experience of the consulting company provides plenty of examples of such behaviour.

\footnotetext{
${ }^{4}$ http://blog.pryaniky.com/bank-idej-proektov/
} 
"They started enjoying the very process of creating a game, from improvisation - it's an emotional and creative process, it reloads the mind after the main job very well, gives $s$ new perspective on the processes." ${ }^{\prime 5}$

If taken further, this approach can become a collaborative play (Deterding, 2014; Hohmann, 2006) or gamestorming (Gray et al., 2010), where participants are offered to try new roles and/or are guided through a scenario of an imaginary situation through a narrative. For instance, in a futuristic alternate reality game "Life without oil" participants were asked to come up with different problems that might be associated with oil shortages and suggest possible solutions to these problems. Through periodic interventions and influx of new information the participants are pushed beyond the boundaries of their comfort zone, leading to many creative solutions (McGonigal, 2011). In this example, scenario updates act as trigger events that aim at stimulating divergent thinking and advancing creative ideas further. By working together, and driven by the common goal, the participants can build on the ideas of each other and imagine the unimaginable. This sort of role-playing has been used in management development for a long time but is becoming more sophisticated with use of interactive games.

Other experiments involve inviting participants to try new roles, e.g. the roles of poor farmers in order to understand the needs of deprived communities in Indonesia (Agogué et al., 2015). By engaging in role-play the participants start empathising with their characters (i.e. the subjects of innovation) through the exploration of an imaginary situation and the personal traits given to them. When combined with their expertise, the role-play helps them to envisage the future in search for new ideas.

\footnotetext{
${ }^{5}$ http://blog.pryaniky.com/povyshaem-prodazh-pri-pomoshhi-gejmifikacii/
} 
To summarise, the first examples of gamifying ideation are somewhat more instrumental and focused primarily on the process of gathering ideas. Distinct game components, e.g. points and badges, are embedded in specific places along the process and act as instruments for participants to engage in new activities. Such design aims at influencing the behaviour of the innovators, i.e. encouraging the participation in different capacities and promoting both collaborative and competitive dynamics. In more playful examples game components are embedded in the background, and instead attention is drawn to a theme and a narrative. These elements aim at facilitating cognitive processes. Through exploration, expression and fantasy, the participants not only express their existing ideas, but also create new ideas, and try to imagine the unimaginable.

\section{Selection}

The selection phase is sometimes embedded in the ideation phase. In the type of initiatives that aim at ideas collection, gamification components provide tools for active selection as a means of participating and expressing one's opinion. This can involve the mechanics of rating (Leimeister, Huber, Bretschneider, \& Krcmar, 2009), investing points and/or time in ideas, or even betting for the best idea (Petersen \& Ryu, 2015). This type of gamified ideas collection alone is rarely used as the primary input of a selection process, but rather as an initial filtering stage or as one of the criteria for the experts' consideration.

In the more playful initiatives, selection might happen more organically and be indistinguishable from ideation. Through collaborative effort some ideas might draw more attention from the participants than others and consequently they naturally advance further. The system designer or facilitator of a scenario-based game and/or role-play might intervene so as to stir the discussion in the direction that they see more 
promising. However, when the participants receive an influx of additional information, e.g. a turn in a narrative, it remains their decision to follow the lead. Their choice is voluntary.

A game can guide the process of selection by providing a framework for thinking critically about each idea, e.g. the organisational readiness, alignment with business, its benefits and the effort required to implement it. A came called "Innovate or Dinosaur" embedded these principles in its board and trigger cards and thus helped to stimulate convergent critical thinking, and to cultivate ownership over the implementation of the ideas (Gudiksen \& Inlove, 2018). This helped to transition to the next phase of the innovating process - implementation.

\section{Implementation}

Implementation refers to the 'physical' development and realisation of the innovative idea. If it follows a product development process, then this phase would typically include planning, concept development, system-level and detailed design, testing and refinement, and production ramp-up (Ulrich \& Eppinger, 2000). These steps resemble the innovating process as a whole, and therefore the examples described above can also be applied to some of these steps, e.g. identifying requirements, exploring design concepts and investigating their feasibility, or building and testing experimental prototypes. One such example includes investing one's time in an idea. Apart from providing an input for the selection phase, this mechanic also helps to identify interested parties and involve a broader audience. With the implementation of this game element companies notice more enthusiasm and willingness among employees to get involved in innovative projects.

"Currently, several business ideas are being developed by volunteers, who asked to lead the implementation of these ideas. 
Before we had "bunnies" [corporate currency], such enthusiasm was much less frequent, it was much more difficult to "shake" the employees and involve them in new project."

Competitive dynamic facilitated through challenges and rewards is used in various steps in the implementation phase. For instance, competitions can be integrated in software testing, a part that is usually regarded as the most boring aspect of software development (Fraser, 2017). Microsoft used this dynamic while testing a new version of Windows. Programmers competed fiercely between the divisions in identifying bugs in the new version for the pride and prestige of their division (Werbach \& Hunter, 2012). Another company, TopCoder, might be the most illustrative example of using gamification to support such activities. It created an online space for programmers who develop solutions for the clients in a form of challenges with rewards. The community of programmers has a rating-based system, which embodies the reputation of each developer. The company uses mechanics such as single-round matches to "glue" the community together, where the programmers can brag about their skills and have fun (Begel, Bosch, \& Storey, 2013).

In the above examples, game elements allow the system to function effectively and help to create a sense of community which is essential for the success of the company. If game elements are further integrated in the implementation phase, the whole product development process can be turned into a game, e.g. a quest with welldefined levels and a set of activities to complete each level, from generating multiple concepts and forming teams, to developing a detailed design and preliminary prototyping (Ionica \& Leba, 2015). Such approach also demonstrates an emphasis on exploitation as opposed to exploration embraced in the ideation phase (March, 1991).

\footnotetext{
${ }^{6}$ http://blog.pryaniky.com/IT-gamification/
} 
These approaches are often linked to the convergent and divergent thinking (Andriopoulos \& Lewis, 2009; Smith \& Tushman L., 2005).

Collaborative dynamic also proved successful in some parts of the implementation process. For instance, a gamified application called iThink was designed for collecting the technical requirements of a product (Fernandes et al., 2012). This application facilitates a critical discussion about product requirements, whereby the participants are asked to share new requirements or to comment on the suggestions of others in exchange for points, under the banner of one of 'The Six Thinking Hats' (De Bono, 1989). This way the system encourages the expression of different types of opinions and provides tools to stir the discussion towards constructive criticism.

One can see the parallel with the ideation phase, whereby, unlike the previous examples that focus on the physical development of a product, the gamified solution attempts to influence cognitive processes. Furthermore, this and other examples are also illustrative of the shift from exploration to exploitation in the implementation phase.

\section{Capture}

The capture phase of innovating implies capturing the impact of the implemented innovation and the value from innovation. Moreover, it might also include aspects such as launch and fostering diffusion of a new product in order to increase the impact that is captured (Tidd et al., 2005). Gamification is widely adopted in marketing (Huotari \& Hamari, 2012), but we are interested in the other side of its application - gamification that helps to create such campaigns. A noteworthy example is Kickstarter, which according Nick Pelling (the creator of the gamification term) encapsulates the essence of gamification (Pelling, 2015). The process of creating a successful campaign is turned into a gamified journey with levels and milestones, 
thereby helping the innovators to capture the results of their innovation. The environment in which innovators meet their supporters emphasises collaboration over competition through elements such as the visualisation of group achievements rather than comparison of individual contributions. The campaigns are put in a spotlight rather than displayed on a leaderboard, so as to promote excellence and give everybody equal opportunities rather than focus on size of the campaigns (Kim, 2018).

The above example facilitates the launch and diffusion of innovation and benefits from collaborative dynamic. The existing examples of innovation capture are built on competitive dynamic, through a contest, where participants were asked to gather and write stories of success by showcasing the results of their work. Such mechanic is particularly successful, if implemented as part of a gamified initiative of the whole innovating process. When the participants are already in a playful state of mind, they can gather stories rich in context and high in value. However, the examples of gamifying innovation capture in the literature are scarce and call for more research in this area.

\section{Where next}

In this paper we analyse early examples in the area of gamified innovating, both from the literature and by capturing original examples from practice. We classify the examples into activity phases using a process model of innovation (Tidd et al., 2005).

At a very high level we see lots of examples within the search/ideation phase. Within the observed examples of gamification for search and ideation we have identified two distinct approaches: (1) facilitation of a physical process, e.g. for ideas collection or product development, and (2) facilitation of cognitive processes through a playful experience so as to stimulate the participants' divergent or convergent thinking. The first approach tries to increase engagement and participation by providing a variety 
of opportunities for participation, e.g. by offering them not only to propose ideas, but also to evaluate ideas of others. Such initiatives can be seen as extensions of open innovation (Chesbrough, 2006) and are often driven by the dynamic of competition or coopetition. The second type of gamified systems used in search and ideation attempts to help participants to change their thinking patterns, e.g. by guiding them through a narrative in an imaginary world so as to help them unleash their creativity. Placing participants in an imaginary world defined by the rules of the gamified system (Salen, Tekinbaş, \& Zimmerman, 2004), with a narrative and a theme, can facilitate thinking in metaphors and imagining the unimaginable. The game becomes a temporary lucid place where objects and behaviour are given special meaning and participants can explore new ideas, scenarios, mindsets, and even challenge organisational assumptions about the future (Gudiksen \& Inlove, 2018). Designed in a collaborative environment outside the participants' comfort zone, such initiatives stimulate unconventional thinking and provide conditions for co-creation of ideas (Prahalad \& Ramaswamy, 2004b, 2004a). In such lucid learning spaces participants might experience one of the highest forms of learning (A. Y. Kolb \& Kolb, 2010), whereby the learning cycle happens through active experimentation, followed by reflections and conceptualisation embedded in situated practice, and results new experiences (Gudiksen \& Inlove, 2018; D. A. Kolb, 2014). Therefore, we suggest exploring further the role of the narratives in each setting.

We have also observed various approaches to gamifying the selection of ideas. Most of the gamification examples found in the selection phase are either coming from crowdsourcing or from process innovation. However, alternative approaches, such as investing points, could help to study the network of innovators and reveal not only the creators of ideas but also other roles, e.g. those who have the ability to recognise good 
ideas, connectors, implementers, promoters etc. Thus gamification could become a performance evaluation tool in an innovating system (Bititci, Garengo, Dörfler, \& Nudurupati, 2012). Further research in this direction could reveal a greater potential for gamification in multiple applications.

There are growing numbers of examples in the implementation phase. Although again more commonly deployed in process innovation rather than product innovation and we expect to see this trend continue. Since most initiatives are focused on ideas management, it seems logical that most ideas proposed by the employees, might be related to the process innovating, which they know well. They might also find implementing such ideas more appealing.

To date we see less activity around the capture phase, which might be the consequence of the trend observed in the implementation phase. If innovating activities are dominated by process innovation, then the results are more evident and can be captured easily without the need for a gamified intervention. If the shift towards the increase in gamified product innovation occurs, it might create the need for more creative solutions in capturing the value.

The examples put forward in this paper may help some practitioners to identify ways they can introduce gamification to the innovating process. Adopting a different model to the analysis of similar examples can be an avenue for further research and might advance our understanding of the potential for using gamification for innovating.

We strongly believe that going forward we need to appreciate the systems view and understand the interconnectedness of some of the elements. We urge other researchers to continue experimenting and to contribute to understanding of how gamification impacts the innovating process in a more systematic manner. 
The findings will be useful for practitioners, as they partially uncover the gamification potential, and illustrate different approaches to gamifying the innovating process. However there is no one panacea, that works for each company will be context dependent (e.g. on sector, company culture, profile of employees, markets they serve etc.). What we are sure of is that gamification holds significant potential doe those wishing to encourage innovation.

Finally, this paper highlighted a few of the negative aspects associated with gamification, which in our opinion can be important learning points that help us advance our understanding of this area in research and practice. From what we have learned about gamification through this study, we conclude that we need to complexify our thinking (Weick, 1995, p. 56) about gamification, explore the variety of interactions, possible structures, time-dependent behaviour and validity of gamification components, and thus paint a richer picture of gamification in the future.

\section{References}

Agogué, M., Levillain, K., \& Hooge, S. (2015). Gamification of Creativity: Exploring the Usefulness of Serious Games for Ideation. Creativity \& Innovation Management, 24(3), 415-429.

Andriopoulos, C., \& Lewis, M. W. (2009). Exploitation-Exploration Tensions and Organizational Ambidexterity: Managing Paradoxes of Innovation. Organization Science, 20(4), 696-717.

Baer, M., Leenders, R. T. H. A. J., Oldham, G. R., Vadera, K., Baer, M., \& Oldham, G. R. (2010). Win or Lose the Battle for Creativity: the Power and Perils of Intergroup Competition. The Academy of Management Journal, 53(4), 827-845.

Begel, A., Bosch, J., \& Storey, M. A. (2013). Social networking meets software development: Perspectives from git hub, MSDN, stack exchange, and top coder. IEEE Software, 30(1), 52-66. 
Bititci, U., Garengo, P., Dörfler, V., \& Nudurupati, S. (2012). Performance measurement: challenges for tomorrow. International Journal of Management Reviews, 14(3), 305-327.

Blohm, I., Bretschneider, U., Leimeister, J. M., \& Krcmar, H. (2010). Does Collaboration among Participants Lead to Better Ideas in IT-based Idea Competitions? An Empirical Investigation. 43rd Hawaii International Conference on System Sciences, 1-10.

Blohm, I., \& Leimeister, J. M. (2013). Gamification: Design of IT-based enhancing services for motivational support and behavioral change. Business and Information Systems Engineering, 5(4), 275-278.

Brown, S. (2009). Play: How It Shapes the Brain, Opens the Imagination and Invigorates the Soul. New York: Avery Press.

Burke, B. (2012). Gamification 2020: What Is the Future of Gamification? Retrieved from https://www.gartner.com/doc/2226015/gamification--future-gamification

Burroughs, J. E., Dahl, D. W., Moreau, C. P., Chattopadhyay, A., \& Gorn, G. J. (2011). Facilitating and Rewarding Creativity during New Product Development. Journal of Marketing, 75(4), 53-67.

Caillois, R. (1961). Man, play, and games. Chicago: University of Illinois Press.

Chesbrough, H. W. (2006). Open innovation: The new imperative for creating and profiting from technology. Boston, MA: Harvard Business Press.

Cohen, J. E. (2016). The Surveillance-Innovation Complex: The Irony of the Participatory Turn. In I. D. Barney, G. Coleman, C. Ross, J. Sterne, \& T. Tembeck (Eds.), The Participatory Condition in the Digital Age (pp. 1-14). University of Minnesota Press.

Cooper, R. G. (1983). A process model for industrial new product development. IEEE Transactions on Engineering Management, 1, 2-11.

De Bono, E. (1989). Six thinking hats. Taylor \& Francis. 
Deterding, S. (2012). Playful Technologies. In Depletion Design. A Glossary of Network Technologies. Institute of Network Cultures, Amsterdam, forthcoming.

Deterding, S. (2014). The Ambiguity of Games: Histories and Discourses of a Gameful World. In S. P. Walz \& S. Deterding (Eds.), The Gameful World. Approaches, Issues, Applications (pp. 23-64). Boston, MA: MIT Press.

Deterding, S., Dixon, D., Khaled, R., \& Nacke, L. (2011). From game design elements to gamefulness. Proceedings of the 15th International Academic MindTrek Conference on Envisioning Future Media Environments - MindTrek '11, 1-7.

Dodgson, M. (2017). Innovation and play. Innovation: Organization \& Management, 19(1), 86-90.

El-Nasr, M., Aghabeigi, B., Milam, D., Erfani, M., Lameman, B., Maygoli, H., \& Mah, S. (2010). Understanding and evaluating cooperative games. $\mathrm{CHI} 2010$ : Proceedings of the 28th International Conference on Human Factors in Computing Systems, 1-10.

Fernandes, J., Duarte, D., Ribeiro, C., Farinha, C., Pereira, J. M., \& Da Silva, M. M. (2012). IThink : A game-based approach towards improving collaboration and participation in requirement elicitation. Procedia Computer Science, 15, 66-77.

Ferrara, J. (2013). Games for Persuasion: Argumentation, Procedurality, and the Lie of Gamification. Games and Culture, 8(4), 289-304.

Fraser, G. (2017). Gamification of Software Testing. IEEE/ACM 12th International Workshop on Automation of Software Testing Gamification, 4-9.

Füller, J., Jawecki, G., \& Mühlbacher, H. (2007). Innovation creation by online basketball communities. Journal of Business Research, 60(1), 60-71.

Gee, J. P. (2008). Learning and games. In K. Salen (Ed.), The Ecology of Games: Connecting Youth, Games, and Learning (pp. 21-40).

Gilson, L. L., \& Litchfield, R. C. (2017). Idea collections: a link between creativity and innovation. Innovation: Organization \& Management, 19(1), 80-85. 
Gray, D., Brown, S., \& Macanufo, J. (2010). Gamestorming: A playbook for innovators, rulebreakers, and changemakers. Sebastopol, CA: O’Reilly Media, Inc.

Gudiksen, S., \& Inlove, J. (2018). Gamification for Business: Why Innovators and Changemakers Use Games to Break Down Silos, Drive Engagement and Build Trust. London: Kogan Page Publishers.

Guilford, J. P. (1968). Intelligence, Creativity, and Their Educational Implications. San Diego, CA: R.R. Knapp.

Hamari, J. (2013). Transforming homo economicus into homo ludens: A field experiment on gamification in a utilitarian peer-to-peer trading service. Electronic Commerce Research and Applications, 12(4), 236-245.

Hargadon, A. B., \& Bechky, B. A. (2006). When Collections of Creatives Become Creative Collectives: A Field Study of Problem Solving at Work. Organization Science, 17(4), 484-500.

Heeter, C., Lee, Y., Medler, B., \& Magerko, B. (2011). Beyond player types: gaming achievement goal. 2011 ACM SIGGRAPH Symposium on Video Games - Sandbox '11, (August 2015), 43-48.

Hohmann, L. (2006). Innovation games: creating breakthrough products through collaborative play. Upper Saddle River, NJ: Addison-Wesley.

Huizinga, J. (1949). Homo Ludens: A study of the play-element in culture. London: Routledge \& Kegan Paul.

Hunicke, R., LeBlanc, M., \& Zubek, R. (2004). MDA: A formal approach to Game Design and Game Research. Proc. AAAI Workshop on Challenges in Game, 1-5. AAAI Press.

Huotari, K., \& Hamari, J. (2012). Defining Gamification - A Service Marketing Perspective. Proceedings of the 15th International Academic MindTrek Conference: Envisioning Future Media Environments, 17-22.

Hutter, K., Hautz, J., Füller, J., Mueller, J., \& Matzler, K. (2011). Communitition: The Tension between Competition and Collaboration in Community-Based Design 
Contests. Creativity \& Innovation Management, 20(1), 3-21.

Ionica, A. C., \& Leba, M. (2015). Gamification \& Research - Partnership for Innovation. Procedia Economics and Finance, 23, 671-676.

Johnson, S. (2016). Wonderland: How Play Made the Modern World. Riverhead Books.

Kim, A. J. (2018). Game Thinking: Innovate Smarter \& Drive Deep Engagement with Design Techniques from Hit Games. gamethinking.io.

Kolb, A. Y., \& Kolb, D. A. (2010). Learning to play, playing to learn: A case study of a ludic learning space. Journal of Organizational Change Management, 23(1), 2650.

Kolb, D. A. (2014). Experiential learning: Experience as the source of learning and development. New Jersey: Pearson Education.

Lee, J. J., \& Hammer, J. (2011). Gamification in education: What, how, why bother? Academic Exchange Quarterly, 15(2), 146-150.

Leimeister, J. M., Huber, M., Bretschneider, U., \& Krcmar, H. (2009). Leveraging Crowdsourcing : Activation-Supporting Components for IT-Based Ideas Competition. Journal of Management Information Systems, 26(1), 197-224.

March, J. G. (1991). Exploration and exploitation in organizational learning. Organization Science, 2(1), 71-87.

McGonigal, J. (2011). Reality is broken: Why games make us better and how they can change the world. New York: The Penguin Press.

McGonigal, J. (2014). I'm not playful, I'm gameful. In S. P. Walz \& S. Deterding (Eds.), The Gameful World. Approaches, Issues, Applications (pp. 653-656). Boston, MA: MIT Press.

McGonigal, J. (2015). SuperBetter: A revolutionary approach to getting stronger, happier, braver and more resilient. New York: Penguin.

Morschheuser, B., Hamari, J., Koivisto, J., \& Maedche, A. (2017). Gamified crowdsourcing: Conceptualization, literature review, and future agenda. 
International Journal of Human Computer Studies, 106, 26-43.

Nath, J. M., \& Metiu, A. (2016). The Invisible Wand: Magic Circles of Play and Work in a High-Tech Organisation. EURAM'16, 1-4 June, Paris.

Nicholson, S. (2012). A User-Centered Theoretical Framework for Meaningful Gamification. Games+Learning+Society 8.0, 1-7.

Pelling, N. (2015). Gamification Past and Present. GWC14. Retrieved from https://www.youtube.com/watch?v=XZ4AbQvUGho

Petersen, S. I., \& Ryu, H. B. (2015). Gamification in Concept Design: Applying Market Mechanisms to Enhance Innovation and Predict Concept Performance. Journal of Design, Business \& Society, 1(1), 95-110.

Prahalad, C. K., \& Ramaswamy, V. (2004a). Co-creation experiences: The next practice in value creation. Journal of Interactive Marketing, 18(3), 5-14.

Prahalad, C. K., \& Ramaswamy, V. (2004b). Co-creating unique value with customers. Strategy \& Leadership, 32(3), 4-9.

Rogers, E. M. (2010). Diffusion of innovations (4th ed.). New York: Simon and Schuster.

Roth, S., Schneckenberg, D., \& Tsai, C. (2015). The Ludic Drive as Innovation Driver : Introduction to the Gamification of Innovation. Creativity and Innovation Management, 24(2), 300-306.

Runco, M. A. (1991). Divergent thinking. Ablex Norwood, NJ.

Runco, M. A., \& Acar, S. (2012). Divergent thinking and creative potential. New York: Hampton Press.

Salen, K., Tekinbaş, K. S., \& Zimmerman, E. (2004). Rules of play: Game design fundamentals. Cambridge, MA: MIT press.

Schulz, K., Geithner, S., Woelfel, C., \& Krzywinski, J. (2015). Toolkit-Based Modelling and Serious Play as Means to Foster Creativity in Innovation Processes. Creativity and Innovation Management, 24(2), 323-340. 
Shpakova, A., Dörfler, V., \& MacBryde, J. (2017). Changing the Game: A Case for Gamifying Knowledge Management. World Journal of Science, Technology and Sustainable Development, 14(2/3), 143-154.

Simpson, B., Tracey, R., \& Weston, A. (2018). Traveling concepts: Performative movements in learning/playing. Management Learning.

Smith, W. K., \& Tushman L., M. (2005). Managing Strategic Contradictions: A Top Management Model for Managing Innovation Streams. Organization Science, $16(5), 522-536$.

Tidd, J., Bessant, J., \& Pavitt, K. (2005). Managing Innovation: Integrating Technological, Market and Organizational Change (3rd ed.). Hoboken: John Wiley \& Sons, ltd.

Ulrich, K. T., \& Eppinger, S. D. (2000). Product design and development. New York: McGraw-Hill/Irwin.

Uzzi, B. (2005). Collaboration and Creativity: The Small World Problem. American Journal of Sociology, 111(2), 447-504.

Van de Ven, A. H. (2017). The innovation journey: you can't control it, but you can learn to maneuver it. Innovation: Organization \& Management, 19(1), 39-42.

Van de Ven, A. H., Angle, H. L., \& Poole, M. S. (2000). Research on the management of innovation: The Minnesota studies. Oxford: Oxford University Press.

Weick, K. E. (1995). Sensemaking in organizations (Vol. 3). Thousand Oaks: Sage Publications Ltd.

Werbach, K., \& Hunter, D. (2012). For the win: How game thinking can revolutionize your business. Philadelphia, PA: Wharton Digital Press.

Zimmerling, E., Hoflinger, P. J., Sandner, P., \& Welpe, I. M. (2016). Increasing the Creative Output at the Front End of Innovation - A Concept for a Gamified Internal Enterprise Ideation Platform. Proceedings of the 49th Annual Hawaii International Conference on System Sciences, 837-846. 
Zuckerman, O., \& Gal-Oz, A. (2014). Deconstructing gamification: evaluating the effectiveness of continuous measurement, virtual rewards, and social comparison for promoting physical activity. Personal and Ubiquitous Computing, 18(7), 17051719. 